\title{
Harnessing Moral Psychology to Reduce Meat Consumption
}

\author{
Joshua May \& Victor Kumar
}

Forthcoming in the Journal of the American Philosophical Association

DOI: $10.1017 /$ apa.2022.2

\begin{abstract}
How can we make moral progress on factory farming? Part of the answer lies in human moral psychology. Meat consumption remains high, despite increased awareness of its negative impact on animal welfare. Weakness of will is part of the explanation: acceptance of the ethical arguments does not always motivate changes in dietary habits. However, we draw on scientific evidence to argue that many consumers are not fully convinced that they morally ought to reduce their meat consumption. We then identify two key psychological mechanisms - motivated reasoning and social proof - that lead people to resist the ethical reasons. Finally, we show how to harness these psychological mechanisms to encourage reductions in meat consumption. A central lesson for moral progress generally is that durable social change requires socially-embedded reasoning.
\end{abstract}

Word count: $8,060(9,970 \mathrm{w} /$ references $)$

Key words: vegetarianism, veganism, moral reasoning, moral progress, meat paradox

\section{Introduction}

Most ethicists and ethical theories agree that the present treatment of nonhuman animals on factory farms is immoral (Schwitzgebel \& Rust 2014; DeGrazia 2009). Even if they are allowed a relatively painless death, poultry and livestock are routinely subject to abuse, mutilation, intense confinement, stress, and untreated ailments - conditions that would normally be considered animal cruelty were they to be inflicted on animals outside farms. Reduced meat consumption would not only mitigate such animal suffering but also limit emission of the greenhouse gases that contribute to the devastating effects of climate change on humans and other animals (Eshel et al. 2019). Even though the precise moral status of animals is contented, it seems that erring on the side of moral caution requires most consumers to be, at the least, reducetarians and decrease their consumption of factory-farmed animals (Matheson 2016).

Consumers are increasingly aware that eating less meat is morally and prudentially desirable. In a recent survey of Americans, for example, most respondents (about 60-70\%) reported "some discomfort with the way animals are used in the food industry" and believe that "factory farming of animals is one of the most important social issues in the world today" (Anthis 2017). Yet, consumption of meat from factory farms remains high throughout the world, and vegetarianism in the vast majority of 
countries remains quite low-e.g., just 5\% of Americans identify as vegetarian (McCarthy and DeKoster 2020). Psychologists have come to call this conflict between attitudes and behavior the "meat paradox" (Loughnan et al. 2010: 156).

The persistence of excessive meat consumption is often construed as a matter of being weak-willed: even with the right attitudes, one cannot muster the strength to change dietary habits (Bratanova et al. 2011; Jaquet 2019). Even among professional ethicists, while most regard vegetarianism as morally superior to an omnivorous diet, few regularly follow the dictates of this moral conviction (Schwitzgebel \& Rust 2014: 97; Bourget \& Chalmers 2022: 8). In general, it seems, acceptance of ethical arguments is insufficient to motivate corresponding behavior (Rust \& Schwitzgebel 2014).

Weakness of will surely explains the behavior of some consumers, but that is only one part of the story. As we discuss below, many consumers do not believe that they are obligated to reduce their meat consumption. Toward the end of his life, the great moral philosopher, James Rachels, published his "basic argument" in favor of vegetarianism. He then wondered, if the argument is "so simple and obvious, why doesn't everyone accept it?" (Rachels 2004: 74). Part of the explanation, he briefly speculated, is that "it is natural for people to resist arguments that require them to do things they don't want to do." He also suspected that "people generally do not respond to ethical appeals unless they see others around them also responding." In what follows, we draw on scientific evidence to argue that Rachels was right. Two psychological mechanisms - motivated reasoning and social proof - are important parts of the explanation for present levels of excessive meat consumption, at least in many parts of the world. However, in an effort to engage in applied moral psychology, we also argue that these mechanisms are integral to moral progress on this issue. Each mechanism can thus be thought of as dual-use moral technologies that can operate in either pernicious or productive ways. A central lesson for moral progress generally is that durable social change requires socially embedded reasoning.

\section{The Basic Moral Argument}

Consumers in various countries, such as America and Brazil, are increasingly trying to reduce their consumption of meat, though not in droves and largely for health reasons (McCarthy and DeKoster 2020; Londoño 2020). Most experimental interventions to reduce meat consumption have accordingly focused on communicating health benefits (Harguess et al. 2020). Prudential gains are certainly important to highlight, but surveys suggest that vegetarians and vegans are more likely to lapse if their only motivation was improved health (Faunalytics 2014; Radnitz et al. 2015), which makes sense. Health science and guidelines change drastically, in part because new evidence comes in, but also because human bodies vary so widely that it's difficult to provide universal recommendations with much certainty, making scientific guidelines malleable. Thus, messaging and policies that appeal only to health will not necessarily lead to durable change in patterns of meat consumption.

Moral values, in contrast, can serve as more stable long-term motivations.

Strongly held moral beliefs can even rise to the level of convictions that evoke strong emotions and persist in the face of various challenges to them (Skitka et al. 2020). Opposition to meat consumption on moral grounds can easily become a conviction, given that the torturous conditions on factory farming amount to a serious moral 
wrong - "more like child abuse than like lying," as Cheryl Abbate aptly puts it (Abbate 2021: 2). Some evidence suggests that vegetarians subsequently become more disgusted by meat if their primary motivation is moral rather than prudential (Rozin et al. 1997; Fessler et al. 2003). More durable reductions in meat consumption might thus require ethical arguments, grounded in appeals to animal welfare (in addition to human welfare and environmental protection). So, although emphasizing health benefits is an important tool in the short-term, our focus will be on the ethical arguments and specifically ones centered on the primary subjects of moral concern: farmed animals.

The Basic Moral Argument against the consumption of meat, at least meat from factory farms, focuses on animal welfare (Rachels 2004; DeGrazia 2009; Abbate 2021):

1. Causing severe and unnecessary harm to animals is wrong. [Moral Premise]

2. Eating meat typically causes severe and unnecessary harm to factory-farmed animals. [Empirical Premise]

Therefore:

3. Eating meat from factory farms is typically wrong.

The first premise is a very plausible moral principle. The second premise is an empirical claim about the harm on factory farms and its connection to meat consumption. We believe the second premise is as plausible as the first, but some philosophers regard it as controversial. On the one hand, there appears to be ample evidence, easily available on the Internet, indicating that factory-farmed animals suffer severe and unnecessary harm. On the other hand, it is contested whether one's choice to eat meat genuinely causes this harm, at least if causation is linked to counterfactual dependence. In general, farms respond to demand from consumers, but it's not clear that a single individual can create a noticeable demand signal, such that refusing to eat meat would have any effect on farming practices (Chignell 2016). As we argue below, dietary choices are socially mediated, which suggests that one's choice to eat meat causes harm on factory farms because it influences the behavior of others. Together, this collective behavior creates a demand signal that increases the number of animals on factory farms who experience severe and unnecessary harm.

That being said, there are variations on the Basic Moral Argument that can sidestep this controversy. As laid out above, the argument has a consequentialist flavor. It suggests that eating meat is wrong because it causes harm. However, there are nonconsequentialist versions of the argument too, which replace causation with complicity:

$1 *$. Supporting a practice that inflicts severe and unnecessary harm to animals is typically wrong. [Moral Premise]

$2 *$ Eating meat supports a practice that inflicts severe and unnecessary harm to factory-farmed animals. [Empirical Premise]

Therefore:

$3^{*}$. Eating meat from factory farms is typically wrong.

Here the argument is that eating meat is wrong because one's purchases support a harmful practice. One is complicit, even if not causally responsible (Driver 2016). Consider Abbate's analogy between factory farming and child abuse. It seems as though 
one would be acting wrongly by participating in a system that abused children, even if the system was not counterfactually dependent on one's behavior. Supporting such a system is at least typically, even if not invariably, wrong. In what follows, we'll rely on our original formulation of the Basic Moral Argument, but nothing turns on accepting the non-consequentialist version instead.

The immediate conclusion of the Basic Moral Argument is that eating meat from factory farms is typically wrong. How one's dietary habits should change, if at all, varies depending on one's circumstances. Some people may have an obligation to adopt a vegetarian or vegan diet. Others might simply have an obligation to reduce their consumption of factory farmed meat incrementally, either by replacing it with meat from humane farms or perhaps aiming long-term to achieve a vegan diet. Reduction of meat consumption is certainly more psychologically realistic. A wholesale change in diet is difficult, especially given prevailing cultural traditions and the inaccessibility of healthy or affordable alternatives. Some people in disadvantaged socioeconomic conditions live in "food deserts" where purchasing cheap meat is arguably necessary. Incremental reduction of meat consumption may nevertheless be possible.

There are, of course, other moral arguments against meat consumption. Factory farms contribute not just to severe and unnecessary animal suffering, but also to water and air pollution; anthropogenic climate change; physical and mental illness of farm workers and people living close to farms; antibiotic-resistant bacteria through overmedication; the threat of global pandemics as viruses pass from intensely confined farm animals to humans; and opportunity costs as federal budgets are inflated by massive government subsidies (Gruen 2011). In sum, there are many plausible moral reasons against eating meat from factory farms. Nonetheless, our focus here is on only the moral argument that relates to animal welfare on factory farms. Our aim is to use psychological research to understand how to instigate and accelerate moral progress on this issue.

\section{We Remain Unconvinced (by the Moral Arguments)}

Are consumers who become aware of the sorts of reasons articulated in the Basic Moral Argument convinced but simply unable to muster the motivation to change? Not necessarily. Anecdotal reports among moral philosophers suggest that both lay people and fellow academics remain unmotivated by the arguments because they are unconvinced, not necessarily weak-willed (Rachels 2004: 74). (We discuss empirical studies that support this idea below.)

Present levels of meat consumption, then, are explained only in part by weakness of will, whether we conceive of this as a failure to act according to one's allthings-considered judgments or intentions (May \& Holton 2012). As we show below, a key problem is that most consumers remain unconvinced by the ethical arguments. Even if initially compelling, doubts and rationalizations later creep in to weaken credence in the premises. Which psychological mechanisms might explain this? Research in moral psychology can help provide an answer.

Over the past two decades, many philosophers and psychologists have recently argued that changes in moral beliefs and behavior are best brought about through powerful emotions, such as empathy or disgust (among these are Haidt 2001; Nichols 2004; Prinz 2007). In one series of experiments, researchers found that participants 
reported being less willing to consume pork or lamb when images of these animals' heads were paired with the corresponding food item (Kunst \& Hohle 2016), and these effects were mediated by increased empathy, disgust, and associating the picture with a living being. Indeed, the researchers further found that the euphemisms we use for food-such as beef and pork instead of cow and pig - curb our empathy toward farmed animals and disgust toward the food products created from them.

Emotions certainly play an important role in reducing meat consumption (and we return to this issue below). However, moral emotions by themselves are unlikely to generate stable, long-term changes in belief and behavior. First consider empathy. Although empathy is known to motivate altruistic behavior (Batson 2011), a wide range of evidence also suggests that empathy is biased (Prinz 2011; Bloom 2016). People are likely to experience empathy in response to vividly depicted victims. When these suffering individuals recede from consciousness, empathy wanes. In addition, empathy tends to be more strongly evoked when animals are cute. Animals who are sentient but ugly are therefore likely to evoke less empathy. For these reasons, empathy (by itself) is not a reliable moral guide.

As mentioned, disgust toward meat and animal cruelty might also seem to be a prime mechanism of change in dietary practices (Rozin et al. 1997; Rottman et al. 2015; Kunst \& Hohle 2016; Tybur et al. 2016). However, to be effective in the moral domain, repugnance must be integrated with processing of the relevant reasons (Kumar 2017). Otherwise, incidental feelings of disgust are unlikely to change moral attitudes, rather than merely entrench existing ones (May 2018a). Appeals to raw disgust are particularly prone to backfire, given that this emotion's functional profile is to distance oneself from its target, and the target of the emotion is pliable. Imagine, for example, that one tries to make consumers revolted by raw meat in a way that doesn't make salient relevant moral reasons to be disgusted by the harrowing conditions of factory farms. Such a campaign risks backfiring if consumers become repulsed, even offended, by the messenger instead of the message.

Fortunately, we now have extensive empirical evidence that a wide range of moral attitudes and behaviors are shaped by reasoning, although often such reasoning is relatively automatic and unconscious (Campbell \& Kumar 2012; Sauer 2017; May 2018b). A recent meta-analysis suggests that attitudes toward meat consumption across many cultures are accordingly responsive to ethical appeals to animal welfare (Mathur et al. 2021). Most of the studies demonstrate only shifts in self-reported attitudes or intentions to reduce meat consumption, at least in the short term, but moral reasoning can affect real behavior.

One recent study conducted at the University of California at Riverside examined the effect of ethical arguments on meatless meal purchases (Schwitzgebel, Cokelet, \& Singer 2020). The researchers randomly assigned more than 1,300 students in introductory philosophy classes to either study either an argument in favor of vegetarianism or, as a control, an argument in favor of charitable giving. Students who studied the argument in favor of vegetarianism purchased slightly fewer meat products in the dining hall in the ensuing weeks. Although the effects were small (about a 7\% reduction that persisted for several weeks), it's remarkable that a reduction in meat consumption was found at all, given how entrenched carnivorism is and given that the intervention focused on studying a philosophical argument. Also notable is that the 
argument for vegetarianism that students studied in this experiment was none other than Rachels's (2004) Basic Argument. As presented above, the argument forces readers to confront the misery on factory farms and reconcile it with the general moral principle that it's wrong to cause a creature severe and unnecessary pain.

So, we shouldn't overlook the power of moral reasoning to effectively change attitudes and behavior. In what follows, we describe two reasoning mechanismsmotivated reasoning and social proof - that influence moral attitudes about meat consumption. We do not mean to suggest that no other psychological mechanisms are at play. Nonetheless, we argue that motivated reasoning and social proof are particularly important. In each case, we first describe the general mechanism and then discuss its application to meat consumption and meat reduction, then we sketch some recommendations for harnessing these socially embedded reasoning mechanisms to reduce meat consumption.

\section{Mechanism 1: Motivated Reasoning}

Human reasoning, whether conscious deliberation or unconscious inference, is often motivated - influenced by one's goals or desires. These motivations can lead people to ask some questions while ignoring others, selectively attend to evidence, and even rationalize personally desirable conclusions (Kunda 1990; Ditto et al. 2009). In some cases of confirmation bias, for instance, one seeks out evidence that supports a belief that one prefers to be true and ignores or discounts disconfirming evidence. People want badly for the election results to turn out in their favor, say, or for the latest quick-fix diet pill to be free of health hazards, and so they adopt the preferred belief and consume news media that supports it. In this way, wishful thinking or willful ignorance can instill a desirable belief and then confirmation bias keeps it safe from challenge, whether in the context of ordinary life or scientific investigation (May 2021).

\subsection{Motivated Moral Reasoning}

We of course see motivated reasoning throughout ethics as well. For example, in order to walk away with more money, participants in one experiment were inclined to cheat a little but not a lot in experimental games, because they can rationalize bending but not breaking the rules (Mazar et al. 2008). We are also inclined to engage in motivated forgetting, by selectively misremembering facts that reveal our past actions to be morally blameworthy, while memories of praiseworthy actions are less spotty (Stanley \& De Brigard 2019). You remember with clarity volunteering at your child's school last year, but you can't seem to recall whether you were fully truthful on your tax returns. Even when considering life and death moral dilemmas, people's responses can depend in part on whether the principle justifies a resolution that best fits their prior political commitments (Ditto et al. 2009). Finally, we can rationalize immoral behavior to ourselves by recalling other virtuous deeds (Blanken et al. 2015). For example, although concerned about your carbon footprint, you reason that driving an electric vehicle morally licenses you to take as many transatlantic flights as you please. These are just some examples of motivated moral reasoning, but the phenomenon is ubiquitous. And notice it isn't always post hoc rationalization, but sometimes ante hoc in that the 
reasoning comes before the decision is made in order to justify making it (May 2018b: 156).

The term "motivated reasoning" is often used in a pejorative sense, calling to mind only apparently pernicious forms, such as wishful thinking. However, motivated reasoning isn't always pernicious, for it can lead to self-knowledge and even scientific knowledge, especially in social contexts where different motives cause competing ideas and arguments to be brought into dialogue (Summers 2017; Mercier \& Sperber 2017; Cushman 2020; May 2021).

Indeed, certain motivations can produce better reasoning than others. Consider, for example, the different motives that influence deliberations about a murder trial. Jury members are supposed to be disinterested, but in reality many want badly for the trial to end swiftly so that they can return to their normal lives. Contrast such self-interested motives, which can lead to lazy reasoning about the case, with the desire of the defendant's mother to exonerate her son. Although she is biased in one sense, her compassion might motivate her to take a more careful look at the evidence, to follow all leads and leave no assumption unquestioned. Another example can be found in the productive forms of scientific reasoning highlighted by feminist epistemologists. Desires to combat sexism can lead researchers to identify biases in knowledgeproduction, often by drawing attention to evidence that is ignored by scientists operating under sexist biases (Anderson 2004). For example, medical research has often excluded women as research participants and systematically ignored conditions that afflict women (Campbell 1998), such as endometriosis.

Thus, the psychological mechanism of motivated reasoning isn't inherently pernicious. It can be productive when non-epistemic motives lead people to ask new questions and attend to overlooked sources of evidence. These can be particularly useful strategies for moving beyond the status quo toward moral progress.

\subsection{Motivated Meat Consumption}

Unsurprisingly, we find some of these mechanisms of motivated moral reasoning in the case of meat consumption. Consumers are highly motivated to continue eating meat for various self-interested reasons, particularly because they enjoy the taste and convenience but also because they don't want to stand out from the crowd or abandon their cultural identities (Faunalytics 2014; Feinberg et al. 2019). But belief in the premises of the Basic Moral Argument (or something like it) is inconsistent with rejection of its conclusion. To avoid cognitive dissonance, consumers would have to discount evidence in favor of the premises or selectively attend to reasons to doubt them (cf. McPherson 2014). They can either doubt that animals on factory farms substantially suffer (rejecting the Empirical Premise) or doubt that such serious suffering is morally problematic (rejecting the Moral Premise). As we detail below, a growing body of research suggests that this is exactly what many consumers do.

Consider first various ways of resisting the Empirical Premise. Although the evidence of suffering on factory farms is plentiful and readily available, it conflicts with desires to continue consuming meat, which gives rise to wishful thinking, willful ignorance, confirmation bias, and other forms of motivated reasoning. Consumers think, for example, that the relevant suffering is not severe because animals don't feel pain quite like humans do. When confronted with moral qualms about meat consumption, 
study participants across multiple countries and cultures ascribe diminished mental capacities to animals, apparently in an effort to reduce cognitive dissonance and thereby rationalize meat consumption (e.g., Bastian et al. 2012; Piazza et al. 2015; Ruby \& Heine 2012).

The suffering that consumers do acknowledge can be further rationalized as rare and ultimately necessary. Many consumers believe that the suffering on factory farms is not severe because it is not systematic. Even though the vast majority of meat comes from factory farms, over half of Americans believe that "most farmed animals are treated well" and three quarters say that they typically buy products using animals that are "treated humanely" (Anthis 2017). Reports of animal abuse on factory farms do make the news, but many consumers seem to remain skeptical of the authenticity of undercover exposés or regard the abuse as carried out by a few bad apples in an otherwise good barrel (Abbate 2021). Studies further suggest that consumers tend to think that suffering caused by factory farms is a side-effect of an industrial food system that is natural or necessary for the growing population of humans. Dubious claims of this sort were the most common justification for eating meat among a sample of American university students (Piazza et al. 2015) and functioned as rationalizations of the status quo (Feinberg et al. 2019). Ultimately, the desire to continue eating meat seems to fuel either willful ignorance of the empirical facts or wishful thinking when confronted with it.

Motivated reasoning likewise lurks in doubts about the Moral Premise. Singer (1974) famously proposed that meat consumption is underwritten by speciesism - a belief that humans, simply by virtue of their biological category, have a higher moral status than other species. Of course, humans have interests that other animals lack, such as a desire to learn a second language. But, importantly, speciesism is the idea that human interests matter more even when they are shared by other animals (such as desires not to be confined or mutilated). Recent empirical evidence suggests that speciesism is a stable belief among many people that explains dietary practices and correlates with other prejudiced attitudes, such as sexism and homophobia (Caviola, Everett, Faber 2019). A line of experimental research further suggests that consumers adopt speciesist attitudes in order to rationalize their consumption of animal products, thereby justifying their behavior and reducing cognitive dissonance (Bratanova et al. 2011; Piazza et al. 2015; Graça et al. 2016). For example, participants in one study reported stronger speciesist beliefs when confronted with ethical, compared to health, reasons for vegetarianism (Jaquet 2019). Even just eating beef jerky, compared to eating cashews, made university students in one study judge that cows deserve slightly less moral consideration (Loughnan et al. 2010).

The emerging psychological picture is that when confronted with moral arguments people rationalize their consumption of products from factory farms. They dementalize the relevant animals and favor speciesist attitudes, for example, in order to justify supporting poor treatment, thereby reducing inconsistency and the cognitive dissonance it produces. As a result, many meat-eaters are able to reject premises of the Basic Argument by believing that either (a) animal welfare matters less than human interests; or (b) eating meat doesn't cause severe harm to farmed animals.

Of course, many other rationalizations are plausibly operative as well, from the rationale that one isn't personally responsible for the suffering on factory farms (see §2) 
to the thought that one does enough moral good elsewhere (moral licensing). Whatever form the motivated reasoning takes, consumers remain unconvinced that they are morally obligated to reduce their meat consumption significantly. Even if one is at times convinced, the belief might not be strong enough to resist later rationalizations. Belief in the premises of the basic moral argument is thus unstable and lacking confidence, which could help explain why most vegetarians/vegans abandon their diet (Faunalytics 2014).

\subsection{Motivated Meat Reduction}

When moral reasoning about the welfare of other creatures is substantially influenced by self-interested motives, the resulting moral beliefs that sustain meat consumption might seem debunked (Jaquet 2019; Kumar \& May 2019). Recall, however, that motivated reasoning isn't always pernicious. Non-epistemic motives can lead people to raise apt questions and consider relevant evidence. Although many people tend to be strongly motivated to consume meat, some are also motivated to maintain relationships with animals, primarily the cats and dogs that live in their homes. Psychological research on the "Contact Hypothesis" suggests that relationships with victims of harm and injustice can foster empathy and other humane attitudes. One way that such contact can engender progressive attitude change is by motivating moral consistency reasoning (Campbell \& Kumar 2012).

To see this, let's consider another case of moral progress: the large and rapid decline in anti-gay attitudes in the U.S. and other countries over the past few decades. One way that anti-gay attitudes have declined is through motivated moral consistency (Kumar, Kodipady, and Young 2020; Kumar and Campbell 2022). Unlike race and ethnicity, sexual orientation is a hidden trait that is evenly distributed across the population. Consequently, many people--no matter what their race, religion, or political orientation--have discovered that a beloved family member or friend is gay. Empathy for the individual in their lives has put people in a better position to understand the ways in which they are harmed and their freedom is curtailed. This local change in attitude has then spurred more general attitude change. People have reasoned that if their family member or friend does not deserve stigma and discrimination, then the many gay people who are strangers do not either. Empathy serves as a spark that leads consistency reasoning in the right direction.

Similarly, personal connections with animals can give people motives to attend to evidence in support of the Basic Argument against eating meat. It is plausible to many pet owners that it would be wrong to kill and torture a cat or dog. Thus, many people strongly oppose the practice of dog fighting, in which pairs of dogs are starved and viciously fight one another, often resulting in the death of one or both animals. Empathy for dogs can motivate one to think carefully about questions of this sort: if it's wrong to inflict severe and unnecessary harm on dogs then isn't it wrong to inflict similar harms on cows, pigs, and chickens? Sincere reflection can then lead people to accept that farm animals suffer (the empirical premise) or that it is wrong to contribute to their suffering (the moral premise).

The mere salience of inconsistency isn't enough to reduce meat consumption. Even if one recognizes an apparent inconsistency among a pair of beliefs, resolution can come from dropping either one of them. Thus, people can live with factory farmed meat 
by accepting that other similar practices (like dog fighting) are also acceptable. A recent set of studies confirms that attitudes toward meat consumption budge little when such inconsistencies are merely made salient (Horne, Rottman, \& Lawrence 2021). However, certain emotional responses can combine with consistency reasoning and lead one in the right direction. Empathy toward farm animals and disgust toward their plight can lead one to resolve the inconsistency in favor of animal interests rather than one's own interests.

A series of fascinating longitudinal studies suggests that both moral emotions and moral principles can help to resist the rationalization of gustatory pleasure (Feinberg, Kovacheff, Teper, \& Inbrar 2019). Each study had participants learn about the suffering farmed animals endure to end up on our plates. In one of the studies, meateaters viewed a series of videos over the course of a month and periodically reported various emotions and attitudes toward eating meat. The main dependent measure was change in "moralization" of meat consumption: how much one treats it as a moral issue. For many people, the lessons had no impact while for others they backfired, making the participants view meat consumption as less of a moral issue. However, in all three studies, the lessons did increase moralization among some participants via two familiar psychological pathways. First, moralizers reported feeling more negative moral emotions (such as guilt, disgust, anger, or sadness) when they thought about eating meat. Second, moralizers were more inclined to say the lessons led them to think more about their "morality and values." Although the researchers did not explicitly measure rationalization or dissonance reduction, it is plausible that the lessons prompted emotional responses that motivated some participants to resolve inconsistencies in their moral values in favor of animal interests over self-interest.

In sum, both reductions in meat consumption and maintenance of the status quo are responsive to motivated reasoning. Self-interested motives (such as taste preferences, the desire to fit in) are liable to rationalize omnivorism, while more otherregarding motives (such as concern for the well-being of farmed animals) can rationalize meat reduction. The motivated reasoning that results can take many forms, from moral licensing and willful ignorance to more charitable interpretations of the mental capacities of farmed animals and more critical distance from one's speciesist attitudes.

\section{Mechanism 2: Social Proof}

It's not just willful ignorance and rationalization that fuel tolerance of factory farms. The fact that excessive meat consumption is commonplace doesn't just encourage apathy; it serves as positive social proof that it's acceptable, that nothing is morally amiss. Indeed, our social context leads many of us to conclude that it's morally obligatory to eat meat, because it's an essential component of Grandma's casserole, Mexican cuisine, or a "masculine" diet. Below we address this more social form of reasoning that also influences moral attitudes toward meat consumption, particularly once social change is already under way. 


\subsection{Evidence from 0thers}

The other important psychological mechanism is a social form of reasoning. As eusocial creatures, we are heavily influenced by our particular in-group, especially those we trust and who are marked with status and prestige (Henrich 2015). One possible reason is that humans were designed by gene-culture co-evolution to learn socially from others. For hundreds of thousands of years, our ancestors have lived in worlds rich with adaptive culture. In this context, it was better to sample the wisdom accumulated over generations instead of attempting to figure things out on one's own.

An important example of social learning is what psychologist Robert Cialdini has called "social proof." The Principle of Social Proof, as he puts it, states: "one means we use to determine what is correct is to find out what other people think is correct" (2009: 88). We're all familiar with the experience of being motivated to dine at a busy restaurant and being turned off by an empty one. Are you just mindlessly following the crowd, or simply acting on a desire to fit in? Not at all. If a restaurant is busy, you take that as evidence that other people like it, which is evidence that you will like it too. Of course, this won't happen if you despise the customers at this restaurant, if say you're driving through a wealthy neighborhood and don't identify whatsoever with such posh patrons. But then we need only turn to who you take to be your in-group. If you're a hipster, then you'll find yourself believing that you must dine at the new restaurant in your neighborhood that has so many fixed-gear bicycles parked out front.

A wide range of evidence suggests that people are more likely to follow social norms if they believe others do as well. One field experiment examined which versions of an environmental conservation message would lead hotel patrons to reuse their towels, instead of having them laundered daily. It turned out that the most effective message was one that added to the environmental reasons a simple claim about the behavior of fellow hotel patrons: that the majority of guests reuse their towels (Goldstein et al. 2008). Similar studies have examined the use of latrines to replace open defecation in developing communities. Although community members can be convinced that it's better for public health to use latrines, usage substantially increases only when everyone also expects that others will follow suit, particularly those in one's in-group or "reference network" (Bicchieri 2017: 14). Equivalent results can be found when people play economic games in a laboratory setting. Participants in one study were slightly more likely to split a pot of money fairly between themselves and another player when they were led to believe that this is what most people from a previous version of the study did (Bicchieri \& Xiao 2009). In general, social change ultimately requires the social evidence that others in one's group have not only adopted the right norms but with enough conviction to adhere to them in practice (Cialdini \& Goldstein 2004; Bicchieri 2017; Tankard \& Paluck 2016). Such social proof is particularly necessary when normative beliefs are weak, novel, uncertain, or unstable - all of which apply in contexts of moral progress against the status quo.

Like motivated reasoning, social proof is not an inherently progressive force. People are also more likely to flout norms if they believe most others do. Think of how cutting in line, jaywalking, and speeding can quickly spread as individuals in a community witness an epidemic of rule-violators. Such widespread breaking of rules serves as proof that the rules aren't important to follow, either because the rule is unnecessary or because punishment is unlikely. 
One fascinating field experiment demonstrates this by measuring theft of petrified wood among more than two thousand visitors of Arizona's Petrified Forest National Park. The researchers found that when visitors saw a sign warning that "Many past visitors have removed the petrified wood from the park, changing the state of the Petrified Forest," theft was eight times higher than when visitors saw a sign pleading "Please don't remove the petrified wood from the park" (Cialdini et al. 2006: 8). When people already violate a rule, it's better to focus attention on the need to comply rather than the fact that others frequently violate it.

The behavior and opinions of the majority aren't the only source of social proof. People are shrewd enough to pay close attention to a subset of community members who are particularly successful, prestigious, trustworthy, or knowledgeable in the relevant domain (Henrich 2015; Bicchieri 2017). Moral exemplars who buck the trend can effect social change, and emulation is more likely if the exemplars are members of one's group that one can relate to personally. For example, students find heroic stories of historical figures like Rosa Parks less inspirational than stories of fellow students who make an impact in their community (Han et al. 2022).

\subsection{Social Meat Consumption}

Unsurprisingly, meat consumption is also influenced by social proof. First consider how it serves as a way to maintain the status quo, as consumers perceive a lack of social evidence in favor of diets low in meat. As noted above, most vegetarians remain a small fraction of the population, which consumers recognize. As Abbate puts it, consumers might think: "if one's parents, friends, doctors, teachers, and religious leaders all eat meat and say that it's okay to eat animals, surely there is something wrong with [the arguments against it]" (2021: 5). And, as we have shown, motivated reasoning can help consumers poke holes in the moral arguments.

Some empirical evidence points to the role of social evidence in meat consumption. In a study of American college students, one of the four most common justifications for their carnivorism was that it's normal - such as "A lot of other people eat meat" and "Meat is culturally accepted" (Piazza et al. 2015: 116). A survey of current and former vegetarians/vegans indicates that the greatest difficulties they face are social: their unusual diet makes them "stick out from the crowd" (Faunalytics 2014). As Melanie Joy (2010) puts it, based partly on interviews with thousands of her university students, meat eating is ultimately considered "a given" (69) or "just the way things are" (65) for members of one's culture or reference group. Men in particular tend to view meat consumption as integral to their masculine identity (Ruby \& Heine 2011). Although the desire to fit in or to avoid shame can trigger motivated reasoning too, the point here is that the attitudes and behavior of group members also serve as social proof.

Many people also receive social evidence against a vegetarian lifestyle. The vast majority of vegetarians/vegans (around 84\%) eventually return to an omnivorous diet (Faunalytics 2014), which serves as powerful social proof that eating animals is natural and necessary for one's well-being. If the vast majority of people in one's community are either meat-eaters or former vegetarians or vegans, then one has powerful social proof that drastically reducing one's meat consumption is not the thing to do. Advocates of the meat industry are already capitalizing on this problem. In 2016 BuzzFeed ran an 
article titled "We Asked Former Vegetarians What Made Them Switch Back To Eating Meat." But this was actually a "paid post" created by Meat \& Livestock Australia (2019), which describes itself as the "marketing, research and development service company for Australia's cattle and sheep producers."

\subsection{Social Meat Reduction}

Social proof can produce the opposite effect, provided one perceives the corresponding change in social norms. Consider a set of randomized field studies conducted at three separate conferences in Denmark. During the registration process, the researchers randomly presented conference goers with a default lunch option that was either vegetarian or non-vegetarian, though in either case participants could actively select the other option. Remarkably, although under $10 \%$ of attendees registered for a vegetarian lunch when meat was the default option, nearly $90 \%$ opted for the vegetarian lunch when it was the default (Hansen et al. 2019). Similar results have been found in a study of university students in campus dining halls (Campbell-Arvai et al. 2014). Participants were nearly twice as likely to select from a meat-free menu when it was the default.

The exact mechanism behind such opt-out effects is not entirely clear. It could be mere laziness: perhaps conference goers overwhelmingly chose the default lunch option because opting out required an active decision. However, in the conference study (Hansen et al. 2019) opting out required little effort - essentially just checking a box. Given what we know about social change in other contexts, the authors of that study plausibly conclude that the default option sends a "normative signal" to conference participants, which is a form of social proof that changes one's beliefs about what others in one's peer group will eat. Moreover, this normative signal arises from the conference organizers, which are members of the conference goers' ingroup with status. This interpretation is bolstered by a study of food choices from hypothetical restaurant menus in the Netherlands (de Vaan et al. 2019). When the menu presented vegetarian dishes as the default (meat could be optionally added to any dish), participants reported this as indicating stronger social norms to eat vegetarian at that restaurant. In general, it may be that default "nudges" influence behavior because they are mediated by an inference about social norms, in which case setting a default is exploiting rational learning mechanisms (Kumar 2016).

Meat consumption can even be reduced by the perception that social norms are trending in the direction of change. One study tracked the lunch purchases of more than three hundred faculty, staff, and students at an on-campus cafe at Stanford University (Sparkman \& Walton 2017). While waiting in line, patrons who agreed to participate in a survey read that $30 \%$ of Americans make an effort to reduce their meat consumption. Some participants were randomly assigned to read this "static" version of the norm, in which the proportion of reducers might seem to be a fixed minority. But participants in the "dynamic norm" condition read that this change is a recent phenomenon, suggesting that an increasing number of Americans are starting to reduce their meat consumption. Strikingly, meatless lunch orders were twice as high when patrons perceived a trend (34\% vs 17\%), and such effects appear to be mediated by the anticipation that meat consumption will decline more in the future and because it matters to other people. A similar effect of norm perception was found on Canadians' intentions to reduce consumption of red meat for environmental reasons (Stea \& Pickering 2019). 
Finally, social proof can help sustain meat reduction if linked to one's ingroup. Vegetarians in India, for example, tend to tie this dietary practice to their group identity, particularly their religion (Ruby et al. 2013). In another cross-cultural study, social influence was associated with meat consumption across individuals residing in America, Canada, Hong Kong, and India. Across all four groups willingness to eat meat was associated with the frequency of consumption among their friends and family (Ruby \& Heine 2012; see also Masson et al. 2016).

\section{Applications to Policy and Messaging}

We have shown that motivated reasoning and social proof can be used more productively to reduce meat consumption for moral reasons. Below we sketch some brief recommendations for how policies and messaging efforts that can harness these psychological mechanisms to encourage durable, long-term changes in dietary practices. The recommendations also illustrate how socially-embedded reasoning can facilitate moral progress.

\subsection{Applications From Motivated Reasoning}

The consumption of animals, and particularly their appalling conditions on factory farms, presents many of us with a tension in our beliefs: we would never treat some animals (such as our pets) this way, but is there a morally relevant difference? When combined with empathy for farmed animals, disgust toward their conditions, and recognition of their mental capacities, one can be led to resolve this inconsistency in favor of animal welfare.

Activists already work to increase awareness about the mental capacities of farmed animals, their conditions on factory farms, and the moral arguments that increase cognitive dissonance. And some evidence does suggest that people who are more knowledgeable about the use of animals as food are less likely to consume animal products (Feltz \& Feltz 2019; Harguess et al. 2020). However, mere exposure to such facts is often insufficient to motivate significant, durable changes in dietary practices. Of course, videos exposing the conditions on factory farms remain powerful, though not merely because they evoke empathy and disgust, but also because such emotional responses to morally-relevant reasons help one resolve inconsistencies in favor of animal welfare. Activists would be likely to inspire more durable change by not just evoking short-lived emotions but motivating people to reason about the similarities between the animals they care about and those who suffer needlessly on factory farms.

What is less emphasized are positive emotions that could lead one's reasoning on a less self-interested path. Empathy can be aroused, for example, if the images and language on menus make salient that the meat came from a once living being. However, empathy is more likely to arise in consumers if they develop relationships with farmed animals. One way is for schools to organize field trips for students to visit humane farms. Or farm animals like pigs can be brought to campus for university students, much in the same way that dogs are brought to campus during exam periods. Although cultural and gustatory motives are powerful, our model suggests that fostering relationships in ways such as these is likely to spur productive motivated reasoning that reduces meat consumption. 


\subsection{Applications From Social Proof}

The behavior of those in one's culture and other ingroups provide powerful social evidence of what's acceptable or required. Few will reduce their meat consumption if their friends, family, and idols maintain the status quo. Even when confronted with a simple and compelling moral argument, one quite reasonably suspects there must be a fatal flaw. But how can social influence get a hold when the vast majority of people in one's community consume meat from factory farms?

Fortunately, as we have shown, social proof can gain a foothold on social change by starting small. Prestigious or popular figures, for instance, can serve as initial influencers by "outing" themselves as meat reducers and promoting the lifestyle. An important feature of social proof is that it, like democracy, dies in darkness. Meat reducers must engage in conspicuous consumption if they are to influence othersalthough, importantly, parading moral attitudes can backfire if perceived as virtue signaling, moral grandstanding, or otherwise off-putting (Minson \& Monin 2012; Tosi and Warmke 2020). Yet calls to reduce meat consumption in the name of animal welfare more commonly succeed rather than backfire, at least in experimental studies that primarily measure self-reported attitudes (Mathur et al. 2021).

Moreover, even if a minority of people in one's community are conspicuous meat reducers, others will be more inclined to follow the trend if they perceive it as a dynamic norm that is increasingly trending in a progressive direction. Institutions can also help to normalize meat reduction and signal changes in consumer norms by, for example, developing meatless Mondays at schools, subsidizing meat alternatives, and making vegetarian options the default at meetings. Finally, since most citizens in one's country will not be meat reducers, it will be beneficial to highlight those smaller ingroups in which a larger proportion are reducers, such as one's alumni network, church group, chess club, or professional organization. The influence that children have on parents might be another promising avenue. Because younger people's dietary choices are more plastic, ethical arguments might change their attitudes and behavior before being filtered into those of their parents.

These recommendations provide only a sketch of some possibilities. Since the consumption of meat, particularly from factory farms, is a profoundly important ethical issue, it is important to attend to the moral psychology of consumers, who are faced daily with the choice of what to put on their plate. Of course, messaging should ultimately appeal not only to the moral reasons in favor of meat reduction but also to benefits for personal health and the environment.

\section{Conclusion}

Significant reductions in meat consumption are widely taken to conflict with gustatory pleasure, cultural traditions, and other values, which together create a recipe for rationalizing maintenance of the status quo. We have identified two key psychological mechanisms - motivated reasoning and social proof - that sustain consumption of factory farmed meat by justifying rejection of, or doubt in, the moral reasons against factory farming. Motivated reasoning allows one to rationalize that animals suffer little 
or that their suffering matters less, while social proof takes the dietary practices of others in one's community as evidence that meat consumption is normal, natural, and necessary. Each psychological mechanism serves to justify unrestricted carnivorism.

These two mechanisms help to explain both wishful thinking and willful ignorance about the ethics of meat consumption. When consumers do become aware of (or later reconsider) the plight of animals on factory farms, both motivated reasoning and social proof can lead them to rationalize their present dietary practices. After all, the treatment of farmed animals isn't a secret, yet everyone else in the community remains unfazed. Other consumers, of course, are not aware of the conditions on factory farms or their ubiquity. However, motivated reasoning and social proof can lead such consumers to think that further inquiry into the issue is unnecessary. After all, hardly anyone in their community is talking about it, so why bother? Thus, although it's true that some people just don't think much about the ethics of meat consumption, our two psychological mechanisms help elucidate this commonsense observation.

It might seem unsurprising that tolerance and implicit support of factory farming is influenced by one's peers and wishful thinking or willful ignorance. These are familiar friends of moral regress and stagnation. What is less obvious is that these are not arational or simplistic mechanisms divorced from reasoning. Indeed, these mechanisms link up with arguments, ideas, evidence, and the reasons they articulate. As a result, social change on this issue, among many others, will require attention to relevant moral reasons and socially-embedded reasoning about them.

\section{Acknowledgements}

An earlier version of this article was presented to the Animal Advocacy Conference, Australiasian Society for Philosophy and Psychology, Society for Philosophy and Psychology, Society for the Study of Ethics and Animals, Department of Bioethics at the National Institutes of Health, Mind and Morality Lab at Boston University, and Experiments in Ethics Workshop at San Raffaele University. Thanks to the organizers and attendees of these events for their feedback. For comments on the manuscript, we thank Trey Braheem, Michael Brownstein, Leticia Castillo Brache, Francesca Davy-Falconi, David DeGrazia, Bob Fischer, Skylar Hawthorne, Daniel Kelly, Alex Madva, Massimo Reichlin, and Aja Watkins. May's work on this project was made possible through the support of a grant from the John Templeton Foundation (Academic Cross-Training Fellowship 61581). The opinions expressed in this publication are those of the authors and do not necessarily reflect the views of the foundation. 


\section{References}

Abbate, C. E. (2021). The Epistemology of Meat Eating. Social Epistemology 35 (1):67-84.

Anderson, E. (2004). Uses of Value Judgments in Science. Hypatia 19(1): 1-24.

Anthis, J. R. (2017). "Survey of US Attitudes Towards Animal Farming and Animal-Free Food." Sentience Institute. https://www.sentienceinstitute.org/animal-farming-attitudessurvey-2017

Bastian, B., Loughnan, S., Haslam, N., \& Radke, H. R. (2012). Don't mind meat? The denial of mind to animals used for human consumption. Personality and Social Psychology Bulletin 38(2): 247-256.

Batson, C. D. (2011). Altruism in Humans. Oxford University Press.

Bicchieri, C., Xiao, E. (2009). Do the right thing: but only if others do so. Journal of Behavioral Decision Making 22(2), 191 - 208.

Bicchieri, C. (2017). Norms in the Wild. Oxford University Press.

Blanken, I., van de Ven, N., \& Zeelenberg, M. (2015). A meta-analytic review of moral licensing. Personality and Social Psychology Bulletin 41(4): 540-558.

Bloom, P. (2016). Against Empathy: The Case for Rational Compassion. Random House.

Bourget, D. \& Chalmers, D. J. (2022). Philosophers on Philosophy: The 2020 PhilPapers Survey. Manuscript.

Bratanova, B., Loughnan, S., Bastian, B. (2011). The effect of categorization as food on the perceived moral standing of animals. Appetite 57(1), 193 - 196.

BuzzFeed. (2016) 'We Asked Former Vegetarians What Made Them Switch Back To Eating Meat'. (Paid post) September 20, 2016.

https://www.buzzfeed.com/beefandlambaustralia/we-asked-former-vegetarians.

Campbell, R. (1998). Illusions of Paradox: A Feminist Epistemology Naturalized. Rowman \& Littlefield Publishers.

Campbell, R., Kumar, V. (2012). Moral Reasoning on the Ground. Ethics 122(2): 273-312.

Campbell-Arvai, V., Arvai, J., \& Kalof, L. (2014). Motivating sustainable food choices: The role of nudges, value orientation, and information provision. Environment and Behavior 46(4): 453-475.

Caviola, L., Everett, J., Faber, N. (2019). The moral standing of animals: Towards a psychology of speciesism. Journal of Personality and Social Psychology 116(6), 1011 - 1029.

Chignell, A. (2016). Can We Really Vote with Our Forks? In Philosophy Comes to Dinner: Arguments about the Ethics of Eating (eds. Chignell, A., Cuneo, T. \& Halteman, M. C.), Routledge, pp. 182-202.

Cialdini, R. B. (2009). Influence. HarperCollins.

Cialdini, Robert B., Linda J. Demaine, Brad J. Sagarin, Daniel W. Barrett, Kelton Rhoads, and Patricia L. Winter. (2006). Managing social norms for persuasive impact. Social Influence, 1, 3-15.

Cialdini, R., Goldstein, N. (2004). Social Influence: Compliance and Conformity. Annual Review of Psychology 55(1), 591 - 621.

Cushman, F. A. (2020). Rationalization is Rational. Behavioral and Brain Sciences, 43 (e28): $1-59$.

DeGrazia, D. (2009). Moral Vegetarianism from a Very Broad Basis. Journal of Moral Philosophy 6: 143-165.

Ditto, P., Pizarro, D., Tannenbaum, D. (2009). Motivated Moral Reasoning The Psychology of Learning and Motivation, Vol. 50 ed. D. M. Bartels, C. W. Bauman, L. J. Skitka, \& D. L. Medin. Academic Press, 307 - 338.

Driver, J. (2016). Individual Consumption and Moral Complicity. In The Moral Complexities of Eating Meat, B. Bramble \& B. Fischer (eds.). Oxford University Press. 
Eshel, G., Stainier, P., Shepon, A., \& Swaminathan, A. (2019). Environmentally optimal, nutritionally sound, protein and energy conserving plant based alternatives to US meat. Scientific Reports 9(1), 1-11.

Faunalytics (2014). Study of Current and Former Vegetarians and Vegans: Initial Findings. https://faunalytics.org/wp-content/uploads/2015/06/Faunalytics_Current-FormerVegetarians_Full- Report.pdf.

Feinberg, M., Kovacheff, C., Teper, R., \& Inbar, Y. (2019). Understanding the process of moralization: How eating meat becomes a moral issue. Journal of Personality and Social Psychology 117(1): 50-72.

Feltz, S., \& Feltz, A. (2019). The Knowledge of Animals as Food Scale. Human-Animal Interaction Bulletin 7(2): 19-45.

Fessler, D. M., Arguello, A. P., Mekdara, J. M., \& Macias, R. (2003). Disgust sensitivity and meat consumption: A test of an emotivist account of moral vegetarianism. Appetite 41(1): 31-41.

Goldstein, N., Cialdini, R., Griskevicius, V. (2008). A Room with a Viewpoint: Using Social Norms to Motivate Environmental Conservation in Hotels. Journal of Consumer Research 35(3), $472-482$.

Graça, J., Calheiros, M., Oliveira, A. (2016). Situating Moral Disengagement: Motivated Reasoning in Meat Consumption and Substitution. Personality and Individual Differences 90(C), 353 - 364.

Gruen, L. (2011). Ethics and Animals: An Introduction. Cambridge University Press.

Haidt, J. (2001). “The Emotional Dog and Its Rational Tail.” Psychological Review 108(4): 814-34.

Han, H., Workman, C., May, J., Scholtens, P., Glenn, A. L., \& Meindl, P. (2022). Which Moral Exemplars Inspire Prosociality? https://psyarxiv.com/dq62n/

Hansen, P., Schilling, M., Malthesen, M. (2019). Nudging healthy and sustainable food choices: three randomized controlled field experiments using a vegetarian lunch-default as a normative signal. Journal of Public Health. DOI: 0.1093/pubmed/fdz154

Harguess, J. M., Crespo, N. C., \& Hong, M. Y. (2020). Strategies to reduce meat consumption: a systematic literature review of experimental studies. Appetite 144: 104478.

Henrich J. (2015). The Secret of Our Success. Princeton University Press.

Horne, Z., Rottman, J., Lawrence, C. (2021). Can coherence-based interventions change dogged moral beliefs? Journal of Experimental Social Psychology.

Jaquet, F. (2019). A debunking argument against speciesism. Synthese 10(2): 1-17.

Joy, M. (2010). Why we love dogs, eat pigs, and wear cows: An introduction to carnism. Red Wheel.

Kumar, V. (2016). "Nudges and Bumps." Georgetown Journal of Law \& Public Policy 14: 86176.

Kumar, V. (2017). Foul Behavior. Philosophers' Imprint 17: 1-17.

Kumar, V. \& Campbell, R. (2022). A Better Ape: The Evolution of the Moral Mind and How it Made Us Human. Oxford University Press.

Kumar, V., Kodipady, A., \& Young, L. (2020). A Psychological Account of the Unique Decline in Anti-Gay Attitudes. https://psyarxiv.com/rvp57/

Kumar, V. \& May, J. (2019). "How to Debunk Moral Beliefs." Methodology and Moral Philosophy, eds. Jussi Suikkanen \& Antti Kauppinen. Routledge, pp. 25-48.

Kunda, Ziva (1990). 'The Case for Motivated Reasoning'. Psychological Bulletin, 108, 480498.

Kunst, J. R. \& Hohle, S. M. (2016). Meat eaters by dissociation: How we present, prepare and talk about meat increases willingness to eat meat by reducing empathy and disgust. Appetite 105: 758-774. 
Londoño, E. (2020). Brazil Is Famous for Its Meat. But Vegetarianism Is Soaring. New York Times. https://www.nytimes.com/2020/12/26/world/americas/brazil-vegetarian.html

Loughnan, S., Haslam, N. \& Bastian, B. (2010). The role of meat consumption in the denial of moral status and mind to meat animals. Appetite 55, 156-159.

Masson, T., Jugert, P., \& Fritsche, I. (2016). Collective self-fulfilling prophecies: group identification biases perceptions of environmental group norms among high identifiers. Social Influence 11(3): 185-198.

Mathur, M. B. et al. (2021). Interventions to Reduce Meat Consumption by Appealing to Animal Welfare: Meta-Analysis and Evidence-Based Recommendations. Appetite 164: 105277.

Matheson, J. (2016). Moral Caution and the Epistemology of Disagreement. Journal of Social Philosophy 47: 120-14.

May, J. (2018a). The Limits of Appealing to Disgust. The Moral Psychology of Disgust, N. Strohminger \& V. Kumar (eds.). Rowman \& Littlefield.

May, J. (2018b). Regard for Reason in the Moral Mind. Oxford University Press.

May, J. (2021). Bias in Science: Natural and Social. Synthese 199: 3345-3366.

May, J. \& Holton, R. (2012). "What in the World Is Weakness of Will?" Philosophical Studies 157(3): 341-360.

Mazar, N., Amir, O. \& Ariely, D. (2008). The dishonesty of honest people: A theory of selfconcept maintenance. Journal of Marketing Research 45: 633-644.

McCarthy, Justin, and Scott DeKoster (2020). Nearly One in Four in U.S. Have Cut Back on Eating Meat. Gallup. https://news.gallup.com/poll/282779/nearly-one-four-cut-backeating-meat.aspx

McPherson, T. (2014). A Case for Ethical Veganism: Intuitive and methodological considerations. Journal of Moral Philosophy, 11(6), 677-703.

Meat \& Livestock Australia. (2019) 'About Us'. https://www.australianbeef.com.au/general/about-us/\#.

Mercier, H., \& Sperber, D. (2017). The Enigma of Reason. Harvard University Press.

Minson, J. A., \& Monin, B. (2012). Do-gooder derogation: Disparaging morally motivated minorities to defuse anticipated reproach. Social Psychological and Personality Science 3(2): 200-207.

Nichols, Shaun (2004). Sentimental Rules. New York: Oxford University Press.

Piazza, J., Ruby, M., Loughnan, S., Luong, M., Kulik, J., Watkins, H., Seigerman, M. (2015). Rationalizing meat consumption. The 4Ns. Appetite 91(C), 114 - 128.

Prinz, J. (2007). The Emotional Construction of Morals. Oxford University Press.

Prinz, J. (2011). Against empathy. The Southern Journal of Philosophy 49: 214-233.

Rachels, J. (2004). The Basic Argument for Vegetarianism. In Food for Thought, S. F. Sapontzis (ed.), Prometheus Books, pp. 70-80.

Radnitz, C., Beezhold, B., \& DiMatteo, J. (2015). Investigation of lifestyle choices of individuals following a vegan diet for health and ethical reasons. Appetite 90: 31-36.

Rottman, J., Kelemen, D., Young, L. (2015). Hindering Harm and Preserving Purity: How Can Moral Psychology Save the Planet? Philosophy Compass 10(2), 134 - 144.

Rozin, P., Markwith, M., Stoess, C. (1997). Moralization and becoming a vegetarian: The transformation of preferences into values and the recruitment of disgust. Psychological Science 8(2), 67 - 73.

Ruby, M., \& Heine, S. (2011). Meat, morals, and masculinity. Appetite 56: 447-450.

Ruby, M., \& Heine, S. (2012). Too close to home. Factors predicting meat avoidance. Appetite 59: 47-52.

Ruby, M., Heine, S., Kamble, S., Cheng, T., \& Waddar, M. (2013). Compassion and contamination: Cultural differences in vegetarianism. Appetite 71: 340-348. 
Rust, J., Schwitzgebel, E. (2014). The Moral Behavior of Ethicists and the Power of Reason. Advances in Experimental Moral Psychology, ed. H. Sarkissian and J. Wright. Continuum, p. 191-208.

Sauer, H. (2017). Moral Judgments as Educated Intuitions. MIT Press.

Schwitzgebel, E., Cokelet, B., Singer, P. (2020). Do Ethics Classes Influence Student Behavior? Case Study: Teaching the Ethics of Eating Meat. Cognition 203: 104397.

Schwitzgebel, E., \& Rust, J. (2014). The moral behavior of ethics professors: Relationships among self-reported behavior, expressed normative attitude, and directly observed behavior. Philosophical Psychology 27(3): 293-327.

Singer, P. (1974). All animals are equal. Philosophic Exchange, 5(1), 103-116.

Skitka, L. J., Hanson, B. E., Morgan, G. S., \& Wisneski, D. C. (2021). The psychology of moral conviction. Annual Review of Psychology 72: 347-366.

Sparkman, G. \& Walton, G. M. (2017). Dynamic Norms Promote Sustainable Behavior, Even if It Is Counternormative. Psychological Science 28, 1663-1674.

Stanley, M. L. \& De Brigard, F. (2019). Moral Memories and the Belief in the Good Self. Current Directions in Psychological Science 28: 387-391.

Stea, S., \& Pickering, G. J. (2019). Optimizing messaging to reduce red meat consumption. Environmental Communication 13(5): 633-648.

Summers, J. S. (2017). Post hoc ergo propter hoc: some benefits of rationalization. Philosophical Explorations, 20(sup1), 21-36.

Tankard, M. E., \& Paluck, E. L. (2016). Norm perception as a vehicle for social change. Social Issues and Policy Review 10(1): 181-211.

Tosi, J. \& Warmke, B. (2020). Grandstanding: The Use and Abuse of Moral Talk (Oxford University Press).

Tybur, J. M., Laakasuo, M., Ruff, J. \& Klauke, F. (2016). How pathogen cues shape impressions of foods: the omnivore's dilemma and functionally specialized conditioning. Evolution and Human Behavior 37: 376-386.

de Vaan, J. M., van Steen, T., \& Müller, B. C. (2019). Meat on the menu? How the menu structure can stimulate vegetarian choices in restaurants. Journal of Applied Social Psychology 49(12): 755-766. 